\title{
ABSENT LEFT PULMONARY ARTERY AND RIGHT-SIDED AORTIC ARCH IN EISENMENGER'S COMPLEX
}

\author{
BY \\ H. A. FLEMING \\ From the Cardiac Department, Brompton Hospital, London
}

(RECEIVED FOR PUBLICATION JANUARY 6, 1958)

\begin{abstract}
Absence of a pulmonary artery is relatively rare, and when McKim and Wiglesworth reported six examples in 1954 they could find only 11 others in the literature since 1868. Most of them had been discovered at operation or necropsy. As Maier (1954) pointed out, the anomaly is found much more frequently in patients submitted to angiocardiography than at necropsy, when it can easily be overlooked. By 1956 Emanuel and Pattinson were able to find 46 cases reported in the literature. Of these, 18 were associated with Fallot's tetralogy, and in all but one it was the left pulmonary artery which was absent; in the exception, there was dextrocardia and situs inversus. The absence of the left pulmonary artery was associated with a right-sided aorta in $60 \%$ of these cases. Most of the other cases that have been reported have also been associated with a major cardiac or vascular defect, although Maier (1954) mentioned one in which no other anomaly could be found. Wyman (1954) likewise reported a case in which absence of the pulmonary artery was the sole defect, and Steinberg, Dotter, and Lukas (1953) described two others in patients aged 26 and 53 years. No associated congenital abnormalities in other systems have been cited.
\end{abstract}

Nadas, Rosenbaum, Wittenborg, and Rudolph (1953) stated that all cases of absent pulmonary artery without a cardiac defect occurred on the right side; one of the two cases described by Steinberg and others (1953), however, had an absent left pulmonary artery. McKim and Wiglesworth (1954) noted that the aortic arch commonly lies on the side opposite to the absent pulmonary artery.

Although studies of associated cardiac lesions have often been incomplete, there is evidence that Fallot's tetralogy is particularly common with this abnormality, a point that should be borne in mind when contemplating Blalock's anastomosis (Nadas and others, 1953). Other associated lesions so far reported include atrial septal defect, patent ductus arteriosus, coarctation of the aorta, pulmonary stenosis, absence of the transverse aortic arch, and persistent truncus arteriosus (Humphreys, 1932 ; Sweet and White, 1950 ; Kjellberg, Mannheimer, Rudhe, and Jonsson, 1955). Eisenmenger's complex has been recorded only once, in a necropsy on a 20-months-old boy with an absent left pulmonary artery and a right-sided aortic arch (McKim and Wiglesworth, 1954).

The purpose of the present paper is to present a case of Eisenmenger's complex with absent left pulmonary artery and right-sided aortic arch in which the diagnosis was established during life. This is believed to be the first such case reported.

\section{CASE RePort}

The patient was a little girl aged 7 years, from Turkey. Since she was not accompanied by her parents or anyone speaking English, it was not possible to obtain a complete history. Cyanosis dated from birth and was increasing; it was particularly noticeable when she was tired or when she exerted herself. There was a dubious history of precordial discomfort on exertion. In the ward she was observed to squat very frequently and she tired easily.

She was small for her age, being $3 \mathrm{ft} .7 \frac{1}{2}$ in. $(110 \mathrm{~cm}$.) in height and weighing $35 \mathrm{lb} .(16 \mathrm{~kg}$.). The sternum protruded markedly, but she had no other external congenital abnormalities. There was moderate central cyanosis and clubbing of the fingers and toes. All peripheral pulses were normal. The blood pressure was $120 / 80 \mathrm{~mm}$. $\mathrm{Hg}$ in both arms. The jugular venous pressure was not raised, but the $a$ wave was abnormally conspicuous. The apex beat was displaced to the left, being formed by a hyperdynamic right ventricle felt in the anterior axillary line. The pulmonary artery impulse was impalpable. On auscultation there was a loud right ventricular third heart sound, increasing on inspiration. In the second left intercostal space was a loud systolic click preceding a short systolic ejection murmur. The 


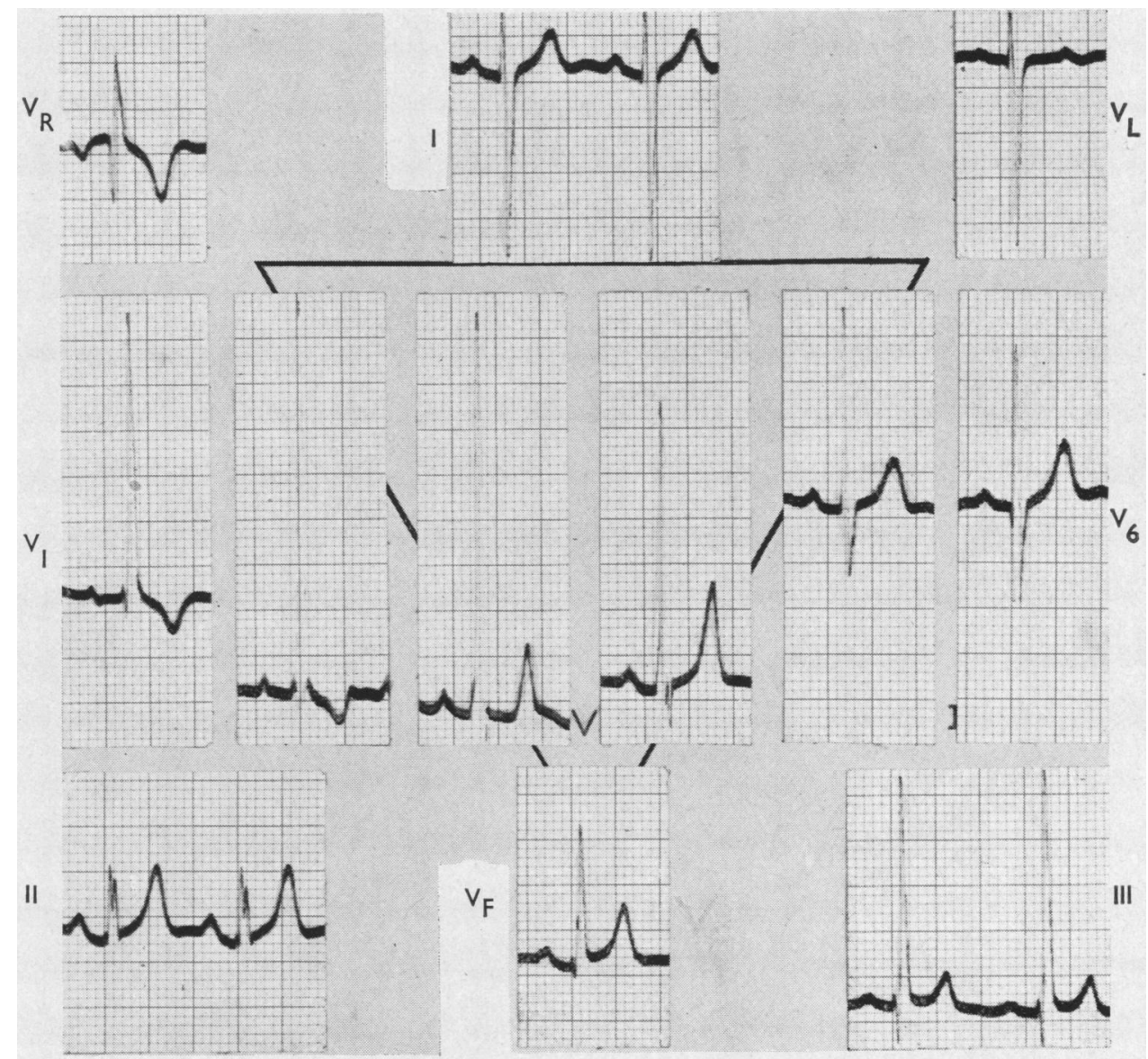

FIG. 1.-Electrocardiogram showing considerable right ventricular hypertrophy.

second sound was loud and single. The movements and the breath sounds on both sides of the chest were normal, and other systems were normal. The haemoglobin was $16.6 \mathrm{~g} . / 100 \mathrm{ml}$. (112\%). An electrocardiogram (Fig. 1) confirmed sinus rhythm and showed considerable right ventricular hypertrophy. Radiography revealed a small left lung with displacement of the heart to the left (Fig. 2). The aortic arch was right sided, the main pulmonary artery was well shown, and the right ventricle was moderately enlarged. The left branch of the pulmonary artery could not be seen, and the vessels in the left lung were extremely small and spidery. The arteries in the right lung appeared to be of normal distribution and were overfilled.

Angiocardiography, using $25 \mathrm{ml}$. of $70 \%$ sodium acetrizoate (Fig. 3), showed a large right atrial appendix. The pulmonary artery and aorta filled simultaneously from the right ventricle, but the bulk of the contrast medium entered the pulmonary artery. No left pulmonary artery could be seen. The right- sided aortic arch crossed to the left of the spine above the diaphragm. The main pulmonary artery merged directly into the right pulmonary artery to form a single uninterrupted curve. The plethoric appearance of the right lung was confirmed and no filling of the vessels in the left lung was seen even in the later films.

Cardiac catheterization was carried out under local anaesthesia and from the right arm. The catheter passed easily from the right ventricle into the aorta whence it was advanced to the descending aorta and the various branches of the arch. It was also passed into the pulmonary artery and wedged in a branch in the right upper lobe. Repeated attempts to enter the aorta from the pulmonary artery were unsuccessful. The pulmonary and aortic valves lay at a rather low level. No other defects could be entered. Pressures were measured from the sternal angle. The oxygen content of the samples was measured by the method of Van Slyke and Neill. The results are shown in Table $I$. 


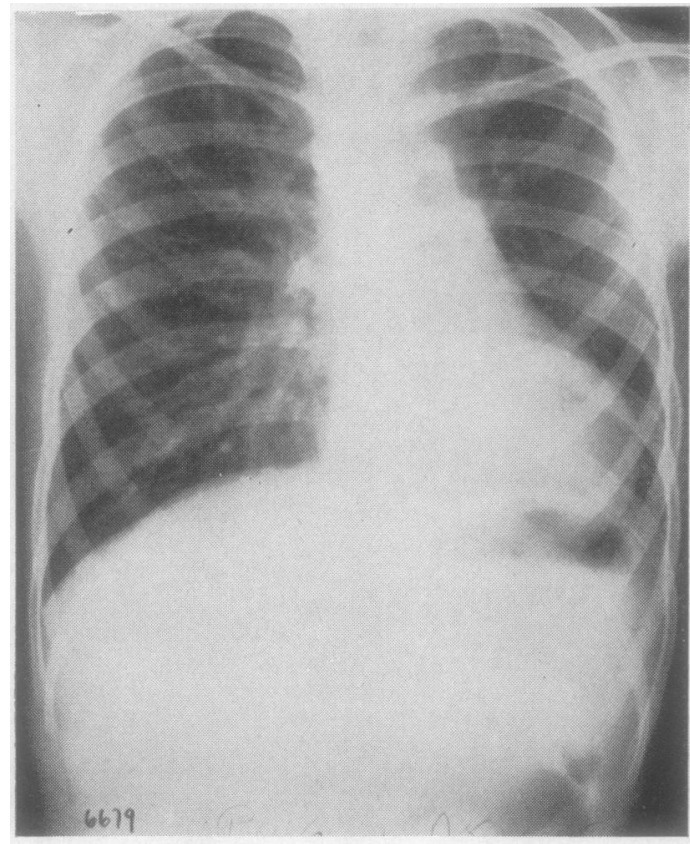

FIG. 2.-Postero-anterior radiograph showing displacement of the heart to the left, right-sided aortic arch, plethoric right lung, and small, translucent left lung.

TABLE I

RESULTS OF CARDIAC CATHETERIZATION

\begin{tabular}{|c|c|c|c|c|}
\hline Site & $\begin{array}{l}\text { Systolic } \\
\text { Diastolic } \\
\text { Pressures } \\
(\mathrm{mm} . \mathrm{Hg})\end{array}$ & $\begin{array}{c}\text { Mean } \\
(\mathrm{mm} . \mathrm{Hg})\end{array}$ & $\mid \begin{array}{c}\mathrm{O}_{2} \text { Content } \\
\text { of Blood } \\
\text { Sample; } \\
\text { (ml. } 1 .)\end{array}$ & $\begin{array}{c}\text { Oxygen } \\
\text { Saturation } \\
(\%)\end{array}$ \\
\hline $\begin{array}{l}\text { Aorta } \\
\text { Pulmonary artery .. } \\
\text { Right ventricle } \\
\text { Pulmonary capillary } \\
\text { Right atrium }\end{array}$ & $\begin{array}{l}82 / 50 \\
82 / 55 \\
85 / 5 \\
+2-1 \\
+4 /-5\end{array}$ & $\begin{array}{r}70 \\
0\end{array}$ & $\begin{array}{l}142 \\
129 \\
120 \\
115\end{array}$ & $\begin{array}{l}72 \cdot 8 \\
66 \cdot 5 \\
61 \cdot 6 \\
5 \overline{59 \cdot 0}\end{array}$ \\
\hline $\begin{array}{l}\mathrm{O}_{2} \text { capacity } \\
\mathrm{O}_{2} \text { uptake } \\
\text { Systemic blood flow } \\
\text { Pulmonary blood flo } \\
\text { Pulmonary vascular }\end{array}$ & $\begin{array}{c}\cdots \\
\cdots \\
\cdots \\
\text { ance }\end{array}$ & \multicolumn{3}{|c|}{ 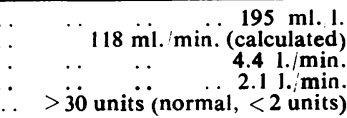 } \\
\hline
\end{tabular}

\section{Discussion}

The initial bedside diagnosis in this case was Fallot's tetralogy with cardiac displacement to the left associated with thoracic deformity; but the conspicuous $a$ wave, hyperdynamic right ventricle, diastolic gallop, and very short ejection murmur were disturbing. The click was attributed to the aorta. The radiograph showed that the displacement of the heart to the left was due to an absent left pulmonary artery and poorly expanded left lung, but did not otherwise alter the diagnosis; indeed, the right-sided aortic arch seemed rather to confirm it. The slightly plethoric right lung

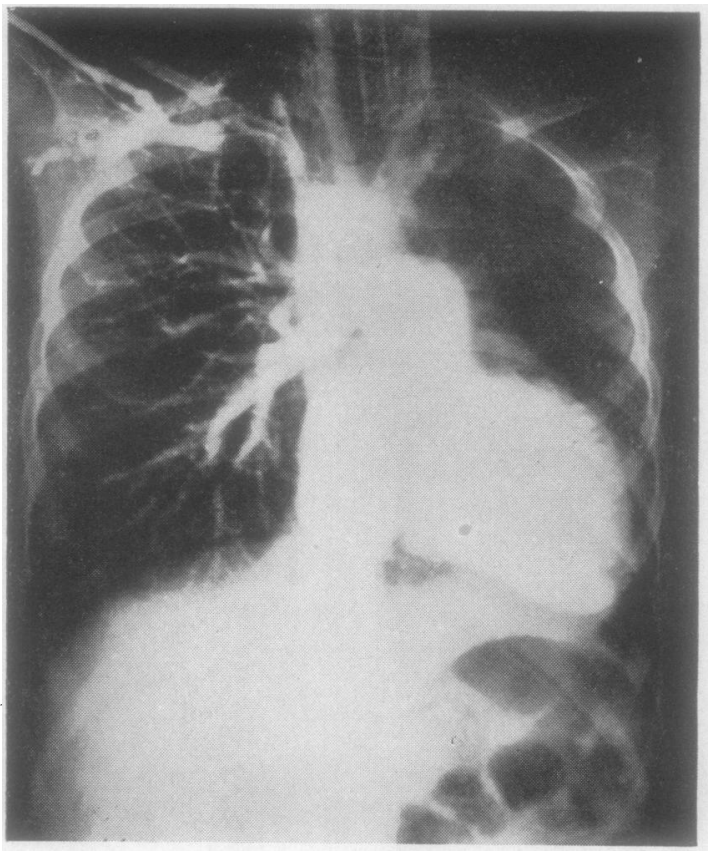

FIG. 3.-Angiocardiogram showing absent left pulmonary artery and simultaneous filling of the aorta and pulmonary artery.

was attributed to the fact that the entire pulmonary blood flow was passing through it. Similar appearances were noticed by Nadas and others (1953) when Fallot's tetralogy was complicated by absence of the left pulmonary artery.

Transposition, persistent truncus arteriosus, and Eisenmenger's complex had to be excluded, and to this end the angiocardiogram was carried out. This confirmed the gross anatomical observations already made and eliminated transposition. Persistent truncus arteriosus was excluded by these same anatomical appearances and also by the strikingly greater opacification of the pulmonary artery than of the aorta in the early films. This is in contrast to the angiocardiogram reproduced by Kjellberg and others (1955) in their case of persistent truncus arteriosus with absent right pulmonary artery. The differential diagnosis between Fallot's tetralogy and Eisenmenger's complex, however, was by no means resolved by the angiocardiogram, for no pulmonary stenosis could be seen. Lowe (1953) found no diagnostic differences between these two conditions on angiocardiography in the absence of visible stricture, and Doyle, Goodwin, Harrison, and Steiner (1957) state that it may be impossible to recognize pulmonary hypertension in congenital heart disease 
from the radiological appearances of the pulmonary vessels.

Cardiac catheterization solved the problem by demonstrating the absence of pulmonary stenosis, the identity of the systolic pressures in the right ventricle, aorta and pulmonary artery, and a considerable right-to-left shunt at ventricular level. The pulmonary vascular resistance was greatly in excess of the systemic, this being the situation in the Eisenmenger syndrome (Wood, 1956). No other defects could be entered and the inability to enter one great vessel from the other was taken as further evidence against persistent truncus arteriosus.

No treatment was advised and the child returned to her home country.

\section{Functional Pathology}

In the few cases of unilateral absence of the pulmonary artery in which the matter has been studied, the major bronchi to the avascular lung are normal and show no more than minor anatomical variations. Madoff, Gaensler, and Strieder (1952) and Nadas and others (1953) have demonstrated this by bronchography. It has also been demonstrated by dissection at necropsy. The lung is usually of less than normal volume but clinically appears to ventilate well; on fluoroscopy there is no mediastinal swing with respiration. Maier (1954) described a case in which the avascular lung decreased progressively in size and when finally removed at operation was found to be diffusely fibrosed. There may be herniation of the normal lung through the mediastinum, but there are no ill effects from this. Steinberg and others (1953) could find only slight physiological evidence of emphysema in a woman aged 53 years. The most complete physiological studies have been made by Madoff and others (1952), who found that the subdivisions of lung volume were near normal, but the minute ventilation at rest and on exercise was increased, the abnormal lung ventilating without participating in the oxygen uptake, as was demonstrated by bronchospirometry.

In many reported cases enlarged bronchial vessels on the affected side have been demonstrated by means of angiocardiography or at necropsy; in a few, a large anomalous branch of the innominate artery has entered the avascular lung. Madoff and others (1952) estimated that $17 \%$ of the total output of the left heart entered the affected lung in their case, and Findlay and Maier (1951) suggested that this increase in the bronchial supply could lead to heart failure. In our case the lung vessels were particularly small and did not opacify at any time in the angiocardiogram. This was so also in cases reported by Steinberg and others (1953) and by Madoff (1954), who checked his observations at necropsy.

In all necropsy cases there has been no central portion of the affected pulmonary artery though the intrapulmonary portion was normally developed. McKim and Wiglesworth (1954) and Emanuel and Pattinson (1956) offer a developmental explanation for this. The former describe, in their left-sided cases, an anomalous obliterated vessel arising from the innominate artery and passing to the intrapulmonary vessels at the hilum. This, they suggest, is an obliterated ductus arteriosus.

\section{CONCLUSIONS}

Cases of unilateral absence of the left pulmonary artery are commonly associated with major cardiac defects (Emanuel and Pattinson, 1956) and a right-sided aortic arch (McKim and Wiglesworth, 1954). They thus present a cardiological problem.

Cases of unilateral absence of the right pulmonary artery commonly have a normal left-sided aortic arch and a normal heart, though there may be other anomalies of the great vessels. They present as a respiratory problem.

The isolated condition is benign and is compatible with normal life and good respiratory function. It may be an incidental finding at routine examination. In these circumstances dysgenesis of the lung, lobar collapse with compensatory over-distension of the rest of the lung, bronchiectasis and unilateral transradiancy (Macleod, 1954) may need to be eliminated. Tomography, bronchography, and bronchospirometry will be helpful in confirming the diagnosis, and angiocardiography will rarely be necessary.

\section{SUMMARY}

A case of Eisenmenger's complex with a rightsided aortic arch and absent left pulmonary artery diagnosed in life is described. The literature is reviewed and the functional pathology and differential diagnosis are discussed.

My thanks are due to Dr. Paul Wood and Sir Russell Brock, under whose care this patient was investigated, and to Dr. Paul Wood for much helpful criticism. I am grateful to Sister V. G. Jones and Mrs. P. M. Milne for technical help with the angiocardiogram and the catheterization. Mr. D. F. Kemp: produced the photographs. 


\begin{abstract}
ADDENDUM
Since this paper was submitted Elder, Brofman, Kohn, and Charms (1958) have reported five cases of unilateral absence or hypoplasia of the pulmonary artery without major cardiac defect. Four of these affected the left side. Two cases had gross bronchiectasis and the others all suffered from haemoptysis with or without pulmonary infection.

\section{REFERENCES}

Doyle, A. E., Goodwin, J. F., Harrison, C. V., and Steiner, R. E. (1957). Brit. Heart J., 19, 353.

Elder, J. C., Brofman, B. L., Kohn, P. M., and Charms, B. L. (1958). Circulation, 17, 557.
\end{abstract}

Emanuel, R. W., and Pattinson, J. N. (1956), Brit. Heart J., 18, 289. Findlay, C. W., and Maier, H. C. (1951). Surgery, 29, 604

Humphreys, E. M. (1932). Arch. Path. (Chicago), 14, 671.

Kjellberg, S. R., Mannheimer, E., Rudhe, U., and Jonsson, B. (1955). The Diagnosis of Congenital Heart Disease. Year Book Publishers, Chicago.

Lowe, J. B. (1953). Brit. Heart J., 15, 319.

McKim, J. S., and Wiglesworth, F. W. (1954). Amer. Heart J., 47, ڤै 845.

Macleod, W. M. (1954). Thorax, 9, 147.

Madoff, I. M. (1954). J. thorac. Surg., $28,161$.

Gaensler, E. A., and Strieder, J. W. (1952). New Engl. J. Med., $247,149$.

Maier, H. C. (1954). J. thorac. Surg., 28, 145.

Nadas, A. S., Rosenbaum, H. D., Wittenborg, M. H., and Rudolph, A. M. (1953). Circulation, 8, 328.

Steinberg, I., Dotter, C. T., and Lukas, D. S. (1953). J. Amer. med. Ass., 152, 1216.

Sweet, R. H., and White, P. D. (1950). New Engl. J. Med., 242, 258. Wood, P. (1956). Diseases of the Heart and Circulation, 2nd ed. Eyre and Spottiswoode, London.

Wyman, S. M. (1954). Radiology, 62, 321. 